\title{
Pre-During-Post Lockdown Air Quality in Adyar, Chennai, India Amid COVID-19 Pandemic
}

\author{
MONIKANDON SUKUMARAN ${ }^{1}$, KESAVAN DEVARAYAN ${ }^{1 *}$, RAMAR MARIMUTHU ${ }^{1}$, \\ SABARISWARAN KANDASAMY ${ }^{2}$ \\ ${ }^{1}$ Tamil Nadu Dr.J. Jayalalithaa Fisheries University, College of Fisheries Engineering, Nagapattinam, Tamil Nadu, 611 002, \\ India \\ ${ }^{2}$ Institute for Energy Research, Jiangsu University, Zhenjiang, China
}

\begin{abstract}
The COVID-19 pandemic has shoved most of the countries to implement restrictions for transportation and all other social activities to minimize spread of disease to the people. India is the second most populated country in the world which has implemented a historical complete lockdown throughout the country from the last week of March to April 2020 with an extension up to the first week of May 2020. This lockdown has slowed down the pollution levels in most of the cities in India within the first few weeks of the lockdown. In this view, the present study discusses the air quality scenario of Chennai, one of the megacities of India, scientifically. With the aid of air quality data of the Tamil Nadu Pollution Control Board, India, for five parameters such as PM 2.5 and P.M 10, sulphur dioxide, nitrogen dioxide and air quality index, the authors correlated the pre-during-post lockdown air quality of Adyar, Chennai. The results indicated that the concentrations of particulate matter reduced to about $50-80 \%$ during the lockdown compared to pre-lockdown. The concentrations of sulphur dioxide and nitrogen dioxide were decreased to $50 \%$ and $20 \%$, respectively, within the first week of lockdown. Further the data were compared with the pollution data for the past two years (2018 and 2019). The present study gives insight on the reduction of pollution in proportion to the temporary control of pollution source at particular interval could rejuvenate the environment.
\end{abstract}

Keywords: air pollution, COVID 19, megacities, Chennai, India

\section{Introduction}

Cities generate wealth, create jobs and accelerate human development by leveraging the process of agglomeration and urbanization. Cities with a population of more than 10 million are called megacities. India is the world's most populous, tropical and peninsular country. As of January 2021, India has five megacities namely, New Delhi, Mumbai, Kolkata, Bengaluru, and Chennai. Chennai is the capital of the state of Tamil Nadu and it is the fifth-largest city in India, which is located at $13.0827^{\circ} \mathrm{N}, 80.2707^{\circ} \mathrm{E}$ on the southern seashore of the Bay of Bengal. Chennai city has an area of about 426 square kilometers with a population of about 10.435 million in 2019 [1]. The population is increasing at the rate of $2.43 \%$ from 2019 and the current population is about 10.9 million people. Chennai is the home for cinema, automobile, education, IT hub and industrial sectors. Apart from the urbanization and economic development, air pollution of the city has magnified in recent decades.

The rapid industrialization and unparallel growth in population have made the city face the consequences of air pollution. Chennai belongs to the most air polluted city in India on emission and energy consumption [2]. Air pollution is complex and cocktail of physical and biological components. Several health problems such as respiratory diseases, infertility, miscarriage and birth defects are associated with air pollution [3]. Air pollution is mainly due to anthropogenic activities and the principal constituents are $\mathrm{SO}_{2} \mathrm{NO}_{2} \mathrm{CO}, \mathrm{PM}_{10}$ and $\mathrm{PM}_{2.5}$. $\mathrm{PM}_{2.5}$ is a mixture of hydrocarbons and other compounds that are emitted from the smoke of vehicles, cooking, industry and other natural components of dust [4].

Most of the health issues related to lungs and respiration are due to $\mathrm{PM}_{2.5}$ [1].

\footnotetext{
*email: kesavan@tnfu.ac.in
} 
$\mathrm{PM}_{2.5}$ is more harmful than $\mathrm{PM}_{10}$. Preceding research done by ref [4] on the vertical transport of $\mathrm{PM}_{2.5}$ and $\mathrm{PM}_{10}$ for the Chennai city has evidenced that the concentrations of $\mathrm{PM}_{2.5}$ were found to be higher than the National Ambient Air Quality Standards (NAAQS). The finer PM concentrations were higher in indoor air and it is mainly due to the emission from vehicular traffic [5]. It should be noted that the residents near the industrial zone at Chennai are exposed more to $\mathrm{PM}_{10}$ concentrations because the outdoor air quality is poor in industrials zones [6].

Sulphur dioxide is a gaseous pollutant and can cause respiratory and lung problems. The acidification of water bodies and soils may occur when Sulphur combines with water present in the air [7]. High temperature industrial process and burning of fuels, which contains sulphur was the major source of this pollutant to be released into the air. Nitrogen dioxide is emitted from vehicles and a high concentration of these pollutants can lead to inflammation of the lungs and prevents its functioning [8].

The effects of air pollution at Chennai have caused respiratory diseases and eye illness to the residents and $\mathrm{PM}_{2.5}$ concentrations were more during summer and these concentrations were higher in industrial areas than residential areas [9]. The air pollution was higher in the premonsoon season due to the influence of sea breeze and circulation of local air particularly in Chennai coastal regions [5]. Coastal meteorology influences air pollutant transport in Chennai [10]. Manali region in Chennai has a high concentration of ammonia in outdoor air and ammonia was released due to the presence of fertilizer industries [8].

Novel Corona Virus (COVID- 19) a pandemic disease was first identified in China in Wuhan in December 2019. Globally over 1605091 people have died and 70829855 have been identified as infected by COVID-19 [11]. Due to an increase in COVID- 19 cases around the world, few countries have imposed complete lockdown. On $22^{\text {nd }}$ March a Nationwide lockdown was announced and Lockdown was imposed in India from $24^{\text {th }}$ March 2020. Due to lock down all the public transports, shopping malls, industries were closed and strict self-quarantine measures were adopted. It was evidenced that after four days of lockdown the air pollution in 88 cities has reduced and the quality of air is improved [2]. The nationwide lockdown has provided an opportunity to find alternative control measures for improving air quality. The objectives of the present study were to compare the pollutants concentrations in air at Adyar, Chennai during the pre-lock down, complete lock down and post-lockdown period. To provide insight and scientific perception to the policymakers and the researchers, the concentration levels of major pollutants from 2018 to 2020 were also used to assess the air quality in Chennai.

\section{Materials and methods}

To assess the air quality, the concentrations of various air pollutants in Chennai especially in Adyar region during the lockdown period the air quality data from $\mathrm{CPCB}$ were used. Particularly the 24 hours average concentrations of Particulate matter $\left(\mathrm{PM}_{2.5}\right.$ and $\left.\mathrm{PM}_{10}\right)$, Sulphur Dioxide, Nitrogen Dioxide and AQI have been obtained from the Tamil Nadu Pollution Control Board. Data used for analysis was from January 2020 to September 2020 and the monthly intermittent day-wise data including pre-lockdown, complete lockdown and post-lock down period. Yearwise data from 2018 to 2020 were also used for comparison of the yearly concentration level of pollutants in the Adyar region.

\section{Results and discussions}

\subsection{Change in concentration of Particulate matter}

The Concentrations of particulate matter $\mathrm{PM}_{10}$ and $\mathrm{PM}_{2.5}$ during January 2020 were $45 \mu \mathrm{g} / \mathrm{m}^{3}$ and $28 \mu \mathrm{g} / \mathrm{m}^{3}$, respectively (Figure 1 and Table 1). The peak concentration of $\mathrm{PM}_{10}$ was $58 \mu \mathrm{g} / \mathrm{m}^{3}$ and it was observed in March 2020 and it has declined during the end of March 2020. According to NAAQS 2009 the peak concentration limit for the particulate matter $\mathrm{PM}_{10}$ is $100 \mu \mathrm{g} / \mathrm{m}^{3}$ and for $\mathrm{PM}_{2.5}$ is $60 \mu \mathrm{g} / \mathrm{m}^{3}$ but both the parameter's concentration levels were within the acceptable limit. On contrary the peak concentration of $\mathrm{PM}_{2.5}$ was $32 \mu \mathrm{g} / \mathrm{m}^{3}$ during the pre-lockdown period, at the end of the pre-lockdown the concentrations decreased to $25 \mu \mathrm{g} / \mathrm{m}^{3}$. 
On average there was a decrease of $50 \%$ in the concentrations of particulate matter, $\mathrm{PM}_{10}$ and $\mathrm{PM}_{2.5}$ have decreased drastically about $80 \%$ during the complete lockdown period when compared to peak concentration at the pre-lockdown period and these shows the effects of lockdown in improving the air quality. However, there was a partial relaxation after two weeks for commodity transport and also controlled industrial operation outside the COVID-19 infected areas and the particulate matter $\mathrm{PM}_{10}$ has shown a slight increase in concentrations of $10 \%$ at the end of April 2020 and $\mathrm{PM}_{2.5}$ has $40 \%$ increase during the initial relaxation period in April 2020 and these shows there is a significant background of traffic, dust resuspension, construction and industrial activities in the origin of particulate matter in a mega city [12] and the $\mathrm{PM}_{10}, \mathrm{PM}_{2.5}$ concentrations of Chennai is in line with the results of the preceding report of air quality during the lockdown for a Megacity in India.

During the phase-wise relaxation of lockdown, the Chennai was categorized under the red zone and there was relaxation only for the transport of commodities in May 2020. Chennai received phase-wise relaxation on $1^{\text {st }}$ June 2020 . From this, the concentrations of $\mathrm{PM}_{10}$ and $\mathrm{PM}_{2.5}$ have gradually increased and notably both the particulate matter concentrations were at their peak in the mid of June 2020 . The peak concentrations of $\mathrm{PM}_{10}$ and $\mathrm{PM}_{2.5}$ were observed to be $65 \mu \mathrm{g} / \mathrm{m}^{3}$ and $32 \mu \mathrm{g} / \mathrm{m}^{3}$, respectively.

The percentage variation of $\mathrm{PM}_{10}$ and $\mathrm{PM}_{2.5}$ concentrations from complete lock down to the phase wise relaxation of lock down the peak concentration has increased by $38.46 \%$ and $53 \%$ respectively. Similar results were obtained for $\mathrm{PM}_{10}$ and $\mathrm{PM}_{2.5}$ for all five regions throughout India and decrease in concentrations of particulate matter has witnessed the effectiveness of lock down [2]. Decrease in concentrations of these pollutants were noticed by ref [13] for Chennai Manali region at pre- and postlock down period. During the month of August 2020 both the particulate matter has reached the peak level in phase wise relaxation of lock down and gradual decrease in concentrations was observed for two months, June 2020 and July 2020. It was interesting to note that at the post lock down particulate matter $\mathrm{PM}_{10}$ concentrations has declined continuously. $\mathrm{PM}_{2.5}$ has also declined at the initial stage of post lock down and started increasing. Comparing the pre lock down and post lock down the concentrations of both the particulate matter were less in post lock down period. But during the entire study period both the particulate matters have not exceeded the NAAQS 2009 limit prescribed for air quality.

According to NAAQS 2009 the maximum permissible limit for the Nitrogen dioxide concentration in air was $80 \mu \mathrm{g} / \mathrm{m}^{3}$. Nitrogen Dioxide peak concentration of about $20 \mu \mathrm{g} / \mathrm{m}^{3}$ was observed at the end of Pre lockdown period and it exhibits similar concentrations at the post lock down period also. $\mathrm{NO}_{2}$ concentrations were less beyond the permissible limit in Chennai $[9,14]$. But the concentrations have significantly reduced within 4 days of complete lock down period to $50 \%$ when compared to the preand post-lock down period. The primary source of Nitrogen Dioxide is emission from vehicles, in particular from diesel fuel operated vehicles and manufacturing industries. During the complete lock down these activities are restricted and this may be the reason for the reduction of concentrations of $\mathrm{NO}_{2}$. Based on the phase wise lockdown relaxation the fluctuation of concentrations was observed in June 2020 and it has almost reached the pre lock down level concentration in August 2020.

Sulphur Dioxide has shown more or less similar concentrations in the pre lock down and posts lock down period. During the complete lock down period sudden declination of $20 \%$ was observed and it was constant during the entire lockdown period and shows a slight variation while the relaxation for commodities transport. In Chennai city the $\mathrm{SO}_{2}$ concentrations were less than the permissible limit which coincides with the results of the preceding studies $[9,15,16]$.

\subsection{Air Quality Index (AQI)}

The air quality Index uses the pollutants such as $\mathrm{Pb}, \mathrm{PM}_{10}, \mathrm{PM}_{2.5}, \mathrm{CO}, \mathrm{SO}_{2}, \mathrm{NO}_{2}, \mathrm{O}_{3}$ and $\mathrm{NH}_{3}$. Out of these three major pollutants are used for AQI computation. The main particulate matter is either $\mathrm{PM}_{10}$ or $\mathrm{PM}_{2.5}$, and the other two air pollutants. The concentrations of these pollutants were converted to a scale of 1-300 for categorizing. The AQI is categorized into good for scale 0-50, Satisfactory for scale between 51-100, Moderate for scale between 101-200 and poor between the scale of 201-300 respectively. The AQI was good at the AQI scale in January 2020 and there were fluctuations in the 
concentration in February and March 2020 at both these months the average scale of AQI was Satisfactory. When Lockdown was imposed there was sudden declination of AQI and in the entire lock down period the concentrations were below and in AQI scale represents good. In June 2020 there were fluctuations and peak value of concentrations was recorded and in AQI scale it has represented a satisfactory level. Interestingly in the post lock down period the concentration level of pollutants was on a good scale in AQI. During the lockdown period there was a reduction of $26 \%$ of the AQI concentrations of the pollutants. The results agree with the previous done for the mega city in India, all the 22 cities have shown 30\% decrease of AQI for the past 4 years and south India especially has shown a decrease of $33 \%$ [2], which was nearer to our results obtained for Adyar region Chennai.

\section{Understanding the Concentrations of $P M_{10}$ over the last 3 years}

To have a better understanding of concentrations of particulate matter over 3 years in Chennai. $\mathrm{PM}_{10}$ average 24h concentrations were obtained from the website of CPCB [17] and analyzed for concentrations. The $\mathrm{PM}_{10}$ concentration was $35 \mu \mathrm{g} / \mathrm{m}^{3}$ in March 2018 and same month in 2019 the concentrations were close to $95 \mu \mathrm{g} / \mathrm{m}^{3}$ but in March 2020 the concentration has declined $45 \mu \mathrm{g} / \mathrm{m}^{3}$ (Figure 2). The percentage decrease in the concentrations during preceding years in at same month was $52.63 \%$ between 2019 and 2020. It can be noticed that increase in the concentration of about $63.15 \%$ has occurred in the same month in 2018 and 2019. During the lockdown period the particulate matter concentration has $25 \mu \mathrm{g} / \mathrm{m}^{3}$ which is below the concentrations for the past 3 years. Similar results of decrease in concentrations were attained by [12] for the Mega Indian city Delhi and it indicates that the lockdown and curfew may be an alternate solution for improving the air quality of Mega cities.

$\mathrm{SO}_{2}$ concentrations levels have shown entirely different patterns of fluctuations for the past 3 years. In 2020 the concentrations were steady $8 \mu \mathrm{g} / \mathrm{m}^{3}$ at pre lock down and post lockdown period. A declination in concentration was observed within the four days of lock down in March 2020 but during the complete down the concentration has declined about 12.5\% in concentration levels. In the year 2019 the concentrations were $9 \mu \mathrm{g} / \mathrm{m}^{3}$ for 6 months and except March 2019. In March 2019 a peak concentration of $10.2 \mu \mathrm{g} / \mathrm{m}^{3}$ was observed, that was the higher concentration ever observed in the past 3 years and the next half year in 2019 the concentration levels have decreased whereas for the other 2 years (2018 and 2020) it was increased at the latter half for both the years.

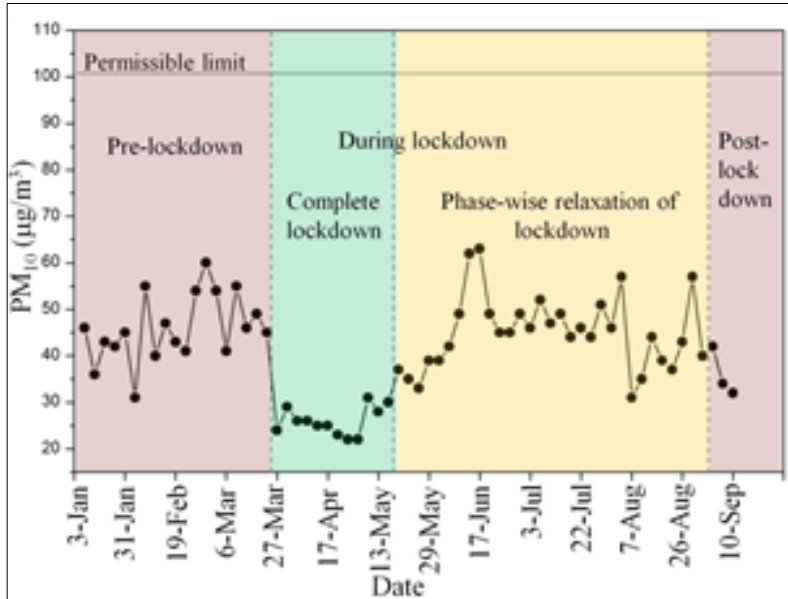

(a)

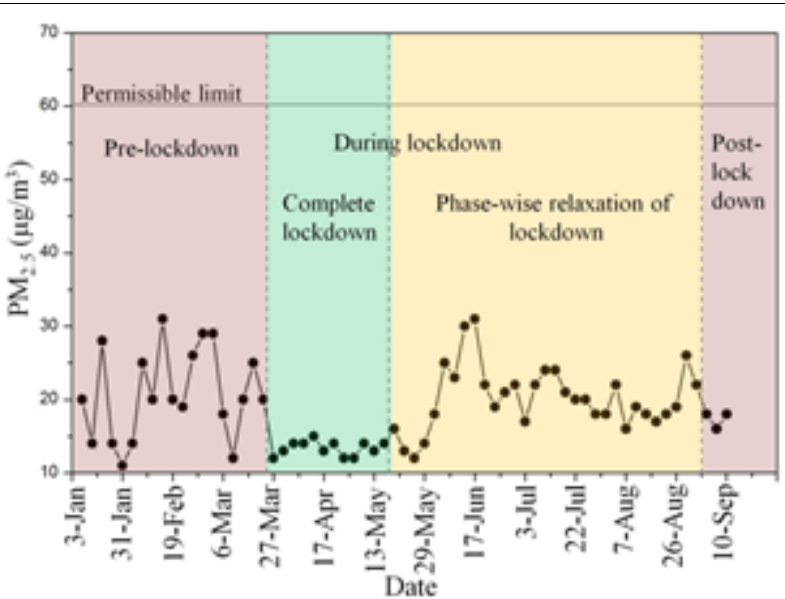

(b) 


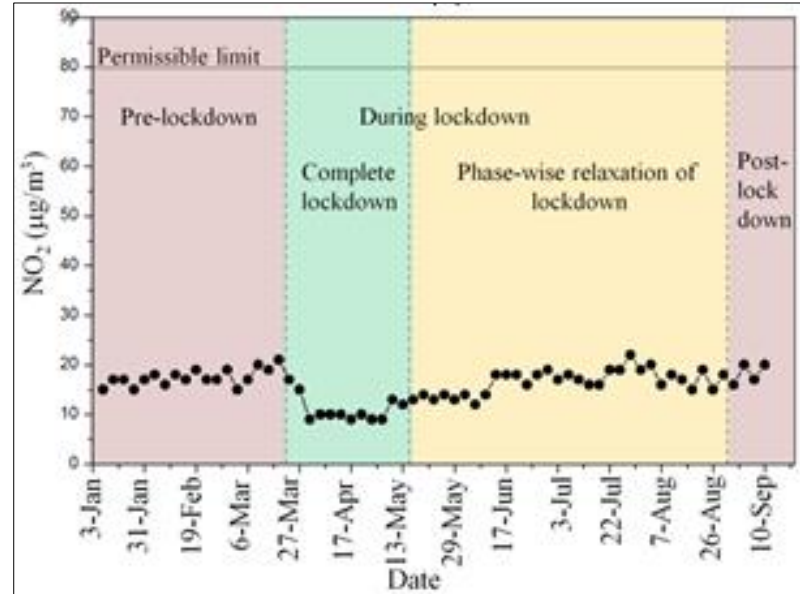

(c)

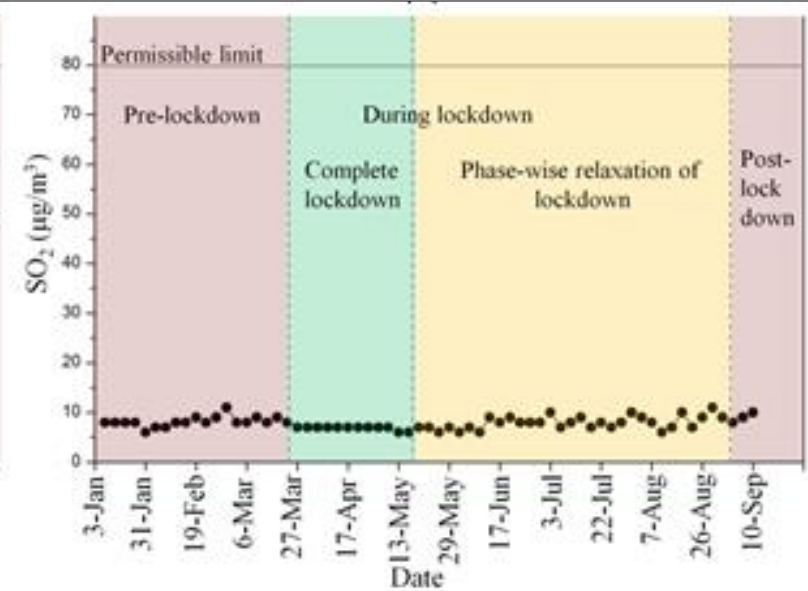

(d)

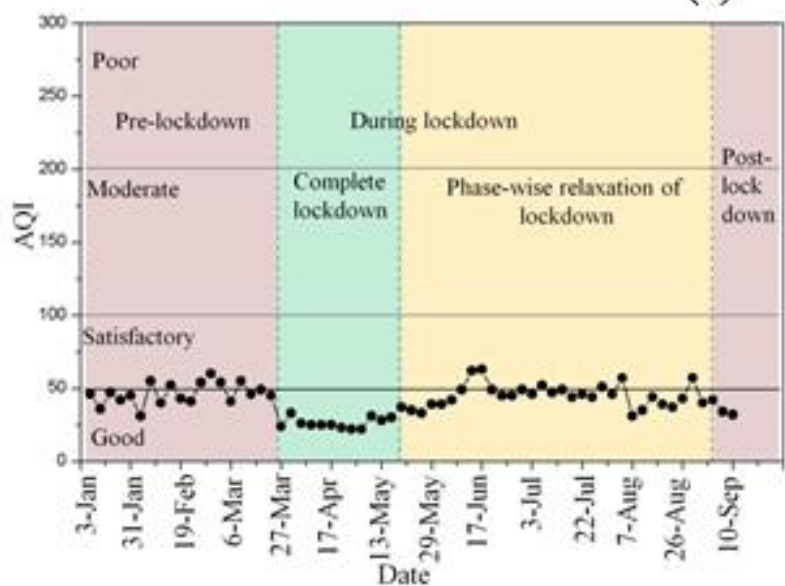

(e)

Figure 1. Air quality trend of Adyar, Chennai, pre-during-post lockdown. $24 \mathrm{~h}$ average concentrations of (a) $\mathrm{PM}_{10}$, (b) $\mathrm{PM}_{2.5}$, (c) $\mathrm{NO}_{2}$, (d) $\mathrm{SO}_{2}$, and (e) AQI. The levels

Table 1. Status of daily air quality parameters pre-, during and post-lockdown

\begin{tabular}{|c|c|c|c|c|c|c|}
\hline Date & & $\mathbf{P M}_{\mathbf{1 0}}$ & $\mathbf{P M}_{\mathbf{2 . 5}}$ & $\mathbf{S O}_{\mathbf{2}}$ & $\mathbf{N O}_{2}$ & $\mathbf{A Q I}$ \\
\hline $3 / 1 / 2020$ & 1 & 46 & 20 & 8 & 15 & 46 \\
\hline $22 / 1 / 2020$ & 2 & 36 & 14 & 8 & 17 & 36 \\
\hline $24 / 1 / 2020$ & 3 & 43 & 28 & 8 & 17 & 47 \\
\hline $29 / 1 / 2020$ & 4 & 42 & 14 & 8 & 15 & 42 \\
\hline $31 / 1 / 2020$ & 5 & 45 & 11 & 6 & 17 & 45 \\
\hline $5 / 2 / 2020$ & 6 & 31 & 14 & 7 & 18 & 31 \\
\hline $7 / 2 / 2020$ & 7 & 55 & 25 & 7 & 16 & 55 \\
\hline $12 / 2 / 2020$ & 8 & 40 & 20 & 8 & 18 & 40 \\
\hline $14 / 2 / 2020$ & 9 & 47 & 31 & 8 & 17 & 52 \\
\hline $19 / 2 / 2020$ & 10 & 43 & 20 & 9 & 19 & 43 \\
\hline $21 / 2 / 2020$ & 11 & 41 & 19 & 8 & 17 & 41 \\
\hline $26 / 2 / 2020$ & 12 & 54 & 26 & 9 & 17 & 54 \\
\hline $28 / 2 / 2020$ & 13 & 60 & 29 & 11 & 19 & 60 \\
\hline $4 / 3 / 2020$ & 14 & 54 & 29 & 8 & 15 & 54 \\
\hline $6 / 3 / 2020$ & 15 & 41 & 18 & 8 & 17 & 41 \\
\hline $11 / 3 / 2020$ & 16 & 55 & 12 & 9 & 20 & 55 \\
\hline $13 / 3 / 2020$ & 17 & 46 & 20 & 8 & 19 & 46 \\
\hline
\end{tabular}




\begin{tabular}{|c|c|c|c|c|c|c|}
\hline $18 / 3 / 2020$ & 18 & 49 & 25 & 9 & 21 & 49 \\
\hline $20 / 3 / 2020$ & 19 & 45 & 20 & 8 & 17 & 45 \\
\hline $27 / 3 / 2020$ & 20 & 24 & 12 & 7 & 15 & 24 \\
\hline $1 / 4 / 2020$ & 21 & 29 & 13 & 7 & 9 & 33 \\
\hline $3 / 4 / 2020$ & 22 & 26 & 14 & 7 & 10 & 26 \\
\hline $8 / 4 / 2020$ & 23 & 26 & 14 & 7 & 10 & 25 \\
\hline $15 / 4 / 2020$ & 24 & 25 & 15 & 7 & 10 & 25 \\
\hline $17 / 4 / 2020$ & 25 & 25 & 13 & 7 & 9 & 25 \\
\hline $22 / 4 / 2020$ & 26 & 23 & 14 & 7 & 10 & 23 \\
\hline $24 / 4 / 2020$ & 27 & 22 & 12 & 7 & 9 & 22 \\
\hline $29 / 4 / 2020$ & 28 & 22 & 12 & 7 & 9 & 22 \\
\hline $8 / 5 / 2020$ & 29 & 31 & 14 & 7 & 13 & 31 \\
\hline $13 / 5 / 2020$ & 30 & 28 & 13 & 6 & 12 & 28 \\
\hline $15 / 5 / 2020$ & 31 & 30 & 14 & 6 & 13 & 30 \\
\hline $20 / 5 / 2020$ & 32 & 37 & 16 & 7 & 14 & 37 \\
\hline $22 / 5 / 2020$ & 33 & 35 & 13 & 7 & 13 & 35 \\
\hline $27 / 5 / 2020$ & 34 & 33 & 12 & 6 & 14 & 33 \\
\hline $29 / 5 / 2020$ & 35 & 39 & 14 & 7 & 13 & 39 \\
\hline $3 / 6 / 2020$ & 36 & 39 & 18 & 6 & 14 & 39 \\
\hline $5 / 6 / 2020$ & 37 & 42 & 25 & 7 & 12 & 42 \\
\hline $10 / 6 / 2020$ & 38 & 49 & 23 & 6 & 14 & 49 \\
\hline $12 / 6 / 2020$ & 39 & 62 & 30 & 9 & 18 & 62 \\
\hline $17 / 6 / 2020$ & 40 & 63 & 31 & 8 & 18 & 63 \\
\hline $19 / 6 / 2020$ & 41 & 49 & 22 & 9 & 18 & 49 \\
\hline $24 / 6 / 2020$ & 42 & 45 & 19 & 8 & 16 & 45 \\
\hline $26 / 6 / 2020$ & 43 & 45 & 21 & 8 & 18 & 45 \\
\hline $1 / 7 / 2020$ & 44 & 49 & 22 & 8 & 19 & 49 \\
\hline $3 / 7 / 2020$ & 45 & 46 & 17 & 10 & 17 & 46 \\
\hline $8 / 7 / 2020$ & 46 & 52 & 22 & 7 & 18 & 52 \\
\hline $10 / 7 / 2020$ & 47 & 47 & 24 & 8 & 17 & 47 \\
\hline $15 / 7 / 2020$ & 48 & 49 & 24 & 9 & 16 & 49 \\
\hline $17 / 7 / 2020$ & 49 & 44 & 21 & 7 & 16 & 44 \\
\hline $22 / 7 / 2020$ & 50 & 46 & 20 & 8 & 19 & 46 \\
\hline $24 / 7 / 2020$ & 51 & 44 & 20 & 7 & 19 & 44 \\
\hline $29 / 7 / 2020$ & 52 & 51 & 18 & 8 & 22 & 51 \\
\hline $31 / 7 / 2020$ & 53 & 46 & 18 & 10 & 19 & 46 \\
\hline $5 / 8 / 2020$ & 54 & 57 & 22 & 9 & 20 & 57 \\
\hline $7 / 8 / 2020$ & 55 & 31 & 16 & 8 & 16 & 31 \\
\hline $12 / 8 / 2020$ & 56 & 35 & 19 & 6 & 18 & 35 \\
\hline $14 / 8 / 2020$ & 57 & 44 & 18 & 7 & 17 & 44 \\
\hline $19 / 8 / 2020$ & 58 & 39 & 17 & 10 & 15 & 39 \\
\hline $21 / 8 / 2020$ & 59 & 37 & 18 & 7 & 19 & 37 \\
\hline $26 / 8 / 2020$ & 60 & 43 & 19 & 9 & 15 & 43 \\
\hline $28 / 8 / 2020$ & 61 & 57 & 26 & 11 & 18 & 57 \\
\hline $2 / 9 / 2020$ & 62 & 40 & 22 & 9 & 16 & 40 \\
\hline
\end{tabular}




\begin{tabular}{|l|l|l|l|l|l|l|}
\hline $4 / 9 / 2020$ & 63 & 42 & 18 & 8 & 20 & 42 \\
\hline $8 / 9 / 2020$ & 64 & 34 & 16 & 9 & 17 & 34 \\
\hline $10 / 9 / 2020$ & 65 & 32 & 18 & 10 & 20 & 32 \\
\hline
\end{tabular}

Notes: $\mathrm{PM}_{2.5}$ - 0-15 - dark green, 16-30 - mild green, 31-60 - orange. $\mathrm{PM}_{10}$ - 0-30 - dark green, 31-50 - mild green, above 51 - orange. $\mathrm{SO}_{2}$ - 0-7 - dark green, 8-40 - mild green. $\mathrm{NO}_{2}$ - 0-15 - dark green, 16-40 - mild green. AQI - 0-30 - dark green, 31-20 - mild green, 51-100 - orange.

The primary source of nitrogen dioxide is emission from vehicles, in particular from diesel fuel operated vehicles and manufacturing industries. During the complete lock down these activities are restricted and this may be a reason for the reduction of concentrations of $\mathrm{NO}_{2}$. Based on the phase wise lockdown relaxation the fluctuation of concentrations was observed in June 2020 and it has almost reached the pre lock down level concentration in August 2020.

\section{Conclusions}

The present study gives insight on the effect of the implementation of lockdown due to COVID-19 pandemic on the air quality of the megacity Chennai, India. Adyar region in Chennai is one of the most populated areas surrounded by the areas that are classified as an industrial areas. The levels of pollutants such as $\mathrm{PM}_{10}, \mathrm{PM}_{2.5}$, sulphur dioxide, and nitrous oxide for the period pre-during and post lock down were correlated. The results indicated that the concentrations of particulate matter decreased up to $80 \%$ and the levels of sulphur dioxide and nitrous oxide decreased up to $40 \%$ within the first week of lock down. Further the average levels of $\mathrm{PM}_{10}$, sulphur dioxide, and nitrous oxide were compared with the previous years and it was noted that the lockdown reduced their levels significantly. From the scientific insights given in this study, it is suggested that reduction in pollution levels can be achieved by the implementation of short term (less than a week) lockdown which could effectively refresh the environment.

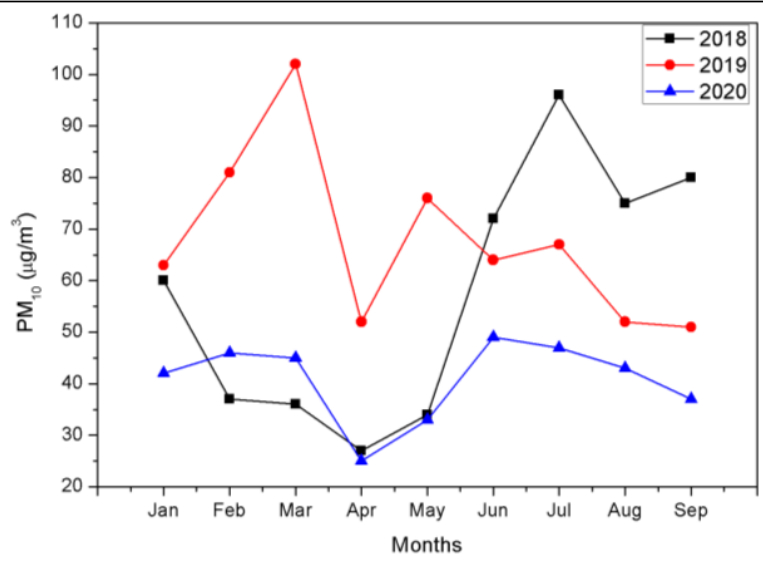

a

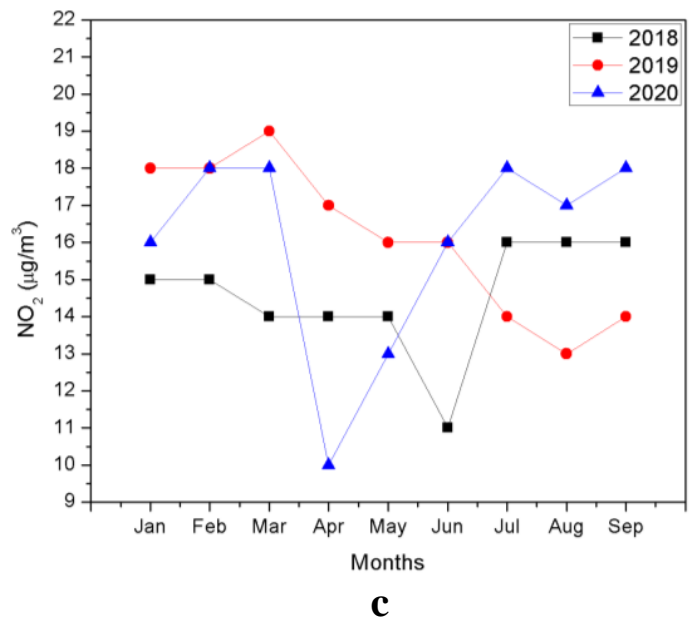

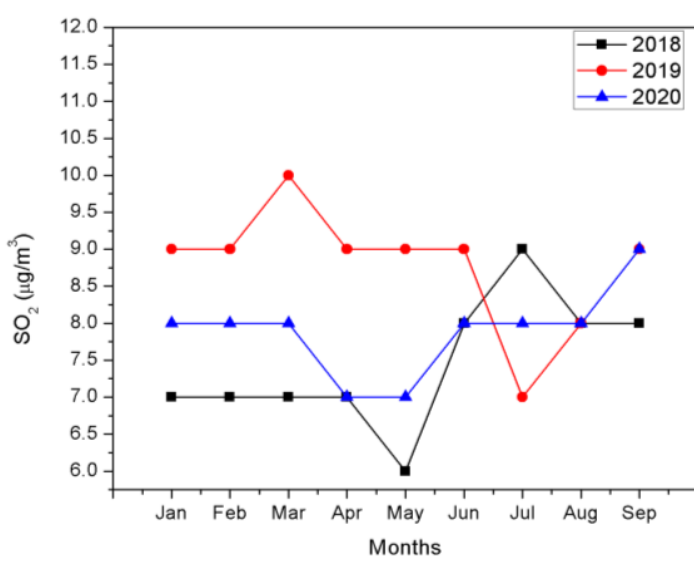

b
Figure 2. Status of yearly $\mathrm{PM}_{10}, \mathrm{SO}_{2}$, and $\mathrm{NO}_{2}$ levels 
Acknowledgments. The authors are thankful to Tamil Nadu Dr.J. Jayalalithaa Fisheries University for encouragement and support towards the research.

\section{References}

1.AMMASI KRISHNAN, M., DEVARAJ, T., VELAYUTHAM, K., PERUMAL, V., SUBRAMANIAN, S., Statistical Evaluation of PM2.5 and dissemination of PM2.5, $\mathrm{SO}_{2}$ and $\mathrm{NO}_{2}$ During Diwali at Chennai, India, Natural Hazards, 2020, doi:10.1007/s11069-020-04149-8

2.SHARMA, S., ZHANG, J., H., KOTA, SH., Eff. Restricted Emiss. COVID-19, Air Qual. India Sci. Total Environ., 138878, 2020.

3.GAO, Q., XU, Q., GUO, X., FAN, H., ZHU, H., Particulate Matter Air Pollution Associated with Hospital Admissions for Mental Disorders: A Time-Series Study in Beijing, China, European Psychiatry, 44, 2017, 68-75. doi:10.1016/j.eurpsy.2017.02.492.

4.EZHILKUMAR, M.R.., et al., Vertical Transport of PM2.5 and PM10 and Its Source Identification in the Street Canyons of Chennai Metropolitan City, India, Atmospheric Pollut. Res., (12)1, 2021, 173183.

5.CHITHRA, V.S., NAGENDRA, S.S., Indoor Air Quality Investigations in a Naturally Ventilated School Building Located Close to an Urban Roadway in Chennai, India, Build. Environ., 54, 2012, 159 167.

6.BALAKRISHNAN, K., GANGULI, B., GHOSH, S., SAMBANDAM, S., ROY, S.S., CHATTERJEE, A., A Spatially Disaggregated Time-Series Analysis of the Short-Term Effects of Particulate Matter Exposure on Mortality in Chennai, India, Air Qual. Atmosphere Health, 6(1), 2013, 111-121.

7.LING-YUN, H.E., JIA-JIA, O.U., Taxing Sulphur Dioxide Emissions: A Policy Evaluation from Public Health Perspective in China, J. Energy \& Environ., 2016, 1-10.

8.ARULPRAKASAJOTHI, M., CHANDRASEKHAR, U., YUVARAJAN, D., TEJA, M.B., An Analysis of the Implications of Air Pollutants in Chennai, Int. J. Ambient Energy, 41(2), 2020, 209-213. 9.MARISELVAM, A.K., KUMAR, M.A., DHARMARAJ, C., MAHARAJ, E., DHASARATHAN, N., SIVANESAN, S., Assessment of Air Quality Index of Urban Area and Epidemiological Investigations in Chennai, J. Environ. Biol., 40(4), 2019, 790-795.

10.MADALA, S., SRINIVAS, C.V., SATYANARAYANA, A.N.V., Performance of WRF for Simulation of Mesoscale Meteorological Characteristics for Air Quality Assessment Over Tropical Coastal City, Chennai, Pure Appl. Geophys., 175(1), 2018, 501-518.

11.***WHO., Coronavirus Disease 2019 (COVID-19) Situation Report -63, 2020, Available at: https://www.who.int/docs/default-source/coronaviruse/situation-reports/20200323-sitrep-63-covid-

19.pdf?sfvrsn=b617302d_4.

12.MAHATO, S., PAL, S., GHOSH, K.G., Effect of Lockdown Amid COVID-19 Pandemic on Air Quality of the Megacity Delhi, India, Sci.of The Total Environ., 139086,2020,

doi:10.1016/j.scitotenv.2020.139086.

13.ARUMUGAM, R., RAJATHI, M., Air Pollution During PrePandemic Covid-19 and In the Lockdown Period at Chennai City: A Statistical Study, J. of Juni Khyat.,10-5(15), 2020, 153-163.

14.PULIKESI, M., BASKARALINGAM, P., ELANGO, D., RAYUDU, V.N., RAMARMUTRTHI, V., SIVANESAN, S., 2006. Air Quality Monitoring in Chennai India in the summer of 2005, J. Hazard matter., 136, 589-596.

15.GEETHA, G., SAMUEL, S.R., Measurement and Analysis of Ambient So2 and Ground Level Ozone in an Urban Air of Chennai India in the year 2010, In: proc. Int.Conf. Green Technol. Environ. Conser, (GTEC) 2011, 185-187.

16.SENTHILNATHAN, T., Measurement of Urban Ambient Air Quality of Chennai City India, J. Air pollut. Control, 7, 2008, 35- 47.

17.CPCB., NAQI Status of Indian Cities in 2015-16. Central Pollution Control Board (CPCB), Ministry of Environment, Forest and Climate Change, Government of India, New Delhi, 2016.

Manuscript received: 17.08 .2021 